\title{
GERMINAÇÃO DE SEMENTES EM PLACAS FECAIS BOVINAS*
}

\author{
GERMINATION OF SEEDS IN BOVINE DUNG \\ Deminicis, B.B. ${ }^{1 A}$, J.C.C. Almeida ${ }^{2 A}$, P.A.M. Malafaia ${ }^{2 B}$, M.C. Blume ${ }^{1 B}$, J.B.R. Abreu ${ }^{2 C}$ \\ e H.D. Vieira ${ }^{1 C}$
}

\begin{abstract}
${ }^{1}$ Universidade Estadual do Norte Fluminense Darcy Ribeiro. UENF. Av. Alberto Lamego, 2000. Campos dos Goytacazes, RJ. CEP 28013-600. Brasil. Abrunodeminicis@hotmail.com; ${ }^{B}$ marinablume@hotmail.com; chenrique@uenf.br

${ }^{2}$ DNAP/IZ. Universidade Federal Rural do Rio de Janeiro, UFRRJ. Brasil. Ajcarvalho@ufrrj.br; Bmalafaia@ufrrj.br; Cjbrabreu@ufrrj.br
\end{abstract}

\section{Palavras chaVe adicionais}

Esterco bovino. Escarificação ruminal. Leguminosas. Pastagem.

\section{RESUMO}

O experimento foi conduzido na UFRRJ e no laboratório de produção e tecnologia de sementes da PESAGRO-RIO, Seropédica, RJ, Brasil, com o objetivo de avaliar a germinação de sementes em placas bovinas fecais, à campo. Foram utilizadas as seguintes leguminosas: Leucaena leucocephala, Clitorea ternatea, Calopogonium mucunoides, Neonotonia wightii e Macrotyloma axillare. As sementes foram administradas aos animais por sonda esofágica (200 sementes/animal) e as fezes foram recolhidas em intervalos de 6 horas até completar 48 horas. As fezes foram alocadas em canteiros de $50 \times 70 \mathrm{~cm}$, num gramado de Paspalum notatum, permanecendo vedados. Foi contado o número de plântulas germinadas, de cada espécie, aos 30,60 e 90 dias após alocação das placas nos canteiros. O delineamento experimental empregado foi inteiramente casualizado, 5 tratamentos (espécies) com 4 repetições. A espécie que apresentou maior porcentagem de plântulas nas fezes foi a Clitorea ternatea, pois aproximadamente $19 \%$ das sementes ingeridas germinaram nas fezes. O período em que foram excretadas as fezes que apresentou maior porcentagem de plântulas foi o de 18 a 24 horas com $29,56 \%$, seguido do período de 24 a 30 horas com $20,44 \%$, lembrando que $100 \%$ é igual a 102 plântulas. Os resultados deste estudo sugerem

*Projeto financiado pela Fundação Carlos Chagas Filho de Amparo à Pesquisa do Estado do Rio de Janeiro, FAPERJ

Recibido: 12-2-07. Aceptado: 21-2-08.

\section{ADDITIONAL KEYWORDS}

Bovine feces. Ruminal scarification. Legumes. Pasture.

que os bovinos podem ser utilizados para a introdução/dispersão de leguminosas de modo prático e barato para a melhora ou recuperação de pastagens degradadas no Brasil.

\section{SUMMARY}

The experiment was conducted at the UFRRJ and the seed laboratory of PESAGRO-RIO, Seropédica, RJ, Brazil, in order to evaluate the germination of seeds in bovine dung, in field. The legumes used were: Leucaena leucocephala, Clitorea ternatea, Calopogonium mucunoides, Neonotonia wightii and Macrotyloma axillare. Seed administration was carried out through esophagic sounding (200 seeds/animal) of only one specie. The droppings were collected at 6 hours intervals up to 48 hours after ingestion. Feces were placed in plots of $50 \times 70 \mathrm{~cm}$ of Paspalum notatum. Germinated seeds were counted at 30,60 and 90 days. The experimental design employed was completely randomised, being 5 treatments (species) with 4 repetitions. The highest germination rate was found in Clitorea ternatea, as approximately $19 \%$ from the ingested seeds germinated in the dung. The highest germinated seeds concentration was found at 18 to $24 \mathrm{hrs}$ with $29.56 \%$ followed by 24 to $30 \mathrm{hrs}$ with $20.44 \%$, remembering what $100 \%$ is equal 102 plants. The results of this study suggests as the bovine can be used for practical and low cost introduction of legumes for improving or recuperation of pastures in Brazil. 


\section{INTRODUÇÃO}

A persistência de espécies forrageiras em pastagens depende de vários fatores, dentre os quais o manejo adequado é indispensável, dessa forma, numa pastagem bem manejada a ressemeadura natural é a forma de renovação e persistência mais importante (Machado et al., 1997). Contudo é um processo extremamente difícil de se observar diretamente ou quantificar (Bruun e Poschlod, 2006). A propagação de plantas pela dispersão de sementes é reconhecida como um dos principais fatores que afetam o recrutamento das plantas e é um importante passo do ciclo reprodutivo da maioria delas (Wenny e Levey, 1998) e quando é realizado por animais torna-se um processo simbiótico, no qual as plantas têm suas sementes dispersas e os dispersores, em troca, recebem retorno nutricional. A dispersão reduz os níveis de predação nas proximidades dos adultos da mesma espécie, aumenta as chances de germinação das sementes, após a passagem pelo trato digestivo dos animais que as ingere (Grelle e Garcia, 1999) e estabelece novos habitats favoráveis a colonização. Além disso, a dispersão de sementes também determina a distribuição espacial dos indivíduos adultos da população (Wenny, 2000).

Após a ingestão das sementes ocorrem danos por mastigação e digestão, assim, a porcentagem de sementes danificadas pelo animal está relacionada à dureza do tegumento, ao formato das sementes e ainda a espécie animal que as ingeriu, à qualidade da dieta consumida e ao tempo de sua permanência no trato digestivo. Nos ruminantes, o tempo de passagem dos alimentos pelo trato digestivo é determinado pela qualidade da dieta (Simão Neto e Jones, 1987; Jones e Simão Neto, 1987). Desta forma, as sementes ingeridas pelos ruminantes, após sofrerem processo digestivo, são defecadas na pastagem, sendo que as que sobrevivem em grande proporção são beneficiadas pela quantidade de nutrientes disponíveis nas fezes e pelo período de rejeição ao pastejo dos animais (Bruun e Poschlod, 2006). A presença das fezes em pontos do pasto normalmente causa rejeição ao consumo animal ficando essa porção não consumida até que o efeito da rejeição diminua com o tempo ou novas áreas mais recentes recebam excretas passando a substituí-los. Essas áreas podem permanecer continuamente de 2 a 3 períodos de pastejo sem serem consumidas (Hirata et al., 1997) e podem variar de 6 à 12 vezes a área coberta pelo bolo fecal (Greenhalgh e Reid, 1968). A degradação ou desaparecimento das fezes no pasto pode estar compreendido em um período de tempo que varia de 30 dias até 17 meses, em função das condições climáticas. Essa porção rejeitada pode ocupar de $10 \mathrm{a}$ $47 \%$ da área da pastagem (Ferreira et al., 2004).

Embora seja reconhecida a importância da ressemeadura natural na renovação e persistência de espécies em pastagens, o papel desempenhado pelos bovinos nesse processo é um assunto pouco conhecido (Blackshaw e Rode, 1991). Portanto, faz-se necessário o conhecimento do desempenho de sementes excretadas por bovinos em pastagens, para que se possa avaliar a dinâmica de semeadura natural subseqüentemente a disseminação de sementes forrageiras (Machado et al., 1997). Desta forma, este estudo teve como objetivo avaliar à campo, a germinação de sementes de 5 leguminosas forrageiras tropicais submetidas à passagem pelo trato digestivo de bovinos, no intuito auxiliar no desenvolvimento de uma metodologia de dispersão/ introdução de leguminosas, por meio da alocação de sementes na alimentação de bovinos para melhora ou recuperação de pastagens.

\section{MATERIAL E MÉTODOS}

As sementes utilizadas neste estudo foram obtidas de populações de plantas, no painel forrageiro da UFFRJ/IZ/DNAP, 


\section{GERMINAÇÃO DE SEMENTES EM PLACAS FECAIS BOVINAS}

coletadas em fase final de maturação, no município de Seropédica, RJ, Brasil. Também foram coletadas sementes no município de Araruama, RJ, em áreas cultivadas com citros há vários anos. Após a coleta as vagens foram secas à temperatura ambiente (18 a $22^{\circ} \mathrm{C}$ ), sendo então extraídas as sementes.

Este estudo foi conduzido no Departamento de Nutrição Animal e Pastagens da UFRRJ, Seropédica, RJ, Brasil. O clima da região é do tipo Aw, pela classificação de Köppen, apresentando duas estações distintas, uma seca, que se estende de abril a setembro e outra quente e chuvosa, que se estende de outubro a março. Levantamentos dos últimos dez anos mostram que a precipitação média anual é de $1217 \mathrm{~mm}$, onde as maiores precipitações ocorrem normalmente no período verão-outono, concentrando-se entre dezembro $(172 \mathrm{~mm})$, janeiro (187 mm) e fevereiro (162 mm), com $42 \%$ da chuva total anual. As temperaturas médias anuais máximas e mínimas são, respectivamente, $29,8^{\circ} \mathrm{Ce} 20,1^{\circ} \mathrm{C}$. O experimento foi realizado entre dezembro de 2004 e março de 2005, foi avaliada a germinação de sementes das leguminosas forrageiras: Leucaena leucocephala (leucena), Clitorea ternatea (cunhã), Calopogonium mucunoides (calopogônio), Neonotonia wightii (soja perene) e Macrotyloma axillare (macrotiloma). O delineamento experimental empregado foi inteiramente casualizado, 5 tratamentos (leguminosas) com 4 repetições, sendo a unidade experimental uma novilha com grau de sangue variando entre 3/4 a 5/8 Holândes-Zebu. Os animais tinham idade variando entre 10 a 12 meses e pesavam em média $150 \mathrm{~kg}$ de peso vivo e foram selecionados na Fazenda do Instituto de Zootecnia da UFRuralRJ, Seropédica, RJ, adotando-se como critério, no momento da seleção, a idade, o peso vivo e o grau de sangue dos animais. Os animais permaneceram em baias individuais de $5 \times 5 \mathrm{~m}$, consumindo água a vontade e uma dieta de capim-elefante, com 140 dias de crescimento, picado em partículas de 2,5 a $5 \mathrm{~cm}$. Cada animal recebeu em torno de $10 \%$ do seu peso vivo em matéria original de capimelefante por dia. O oferecimento do alimento foi realizado às 09:00 horas da manhã. Após um período de adaptação de 7 dias, cada novilha recebeu 200 sementes intactas, ou seja, não escarificadas, de somente uma espécie e de uma só vez, assim, as sementes foram submetidas à passagem pelo trato digestivo dos bovinos.

A administração das sementes foi realizada no dia 11/12/2004 às 09:00 horas da manhã, por meio de uma cânula esofágica $(35 \mathrm{~cm})$, em cartuchos de papel-toalha, a partir daí foram realizadas coletas totais de fezes a cada 6 horas até o intervalo de 48 horas, a coleta de fezes se encerrou no dia 13/12/2004 às 09:00 horas da manhã. As fezes coletadas foram transportadas em bandejas plásticas de $50 \times 40 \mathrm{~cm}$ até o campo de observação. As fezes coletadas serviram para a confecção de bolos fecais artificiais, ou seja, das placas fecais, com o auxílio de um recipiente plástico, figura 1 . O recipiente plástico utilizado para constituir artificialmente as placas fecais, possuía a forma de corte de cone com as seguintes dimensões: $\mathrm{R}=7 \mathrm{~cm}, \mathrm{r}=5,5 \mathrm{~cm} \mathrm{e} \mathrm{h}=5,5 \mathrm{~cm}$, ou seja, com o volume de $678 \mathrm{~cm}^{3}$ e ocupando uma área de $153 \mathrm{~cm}^{2}$ no canteiro. A formação das placas fecais artificiais, alocadas nos canteiros, foi a forma encontrada para resolver o problema ocasionado pelo pisoteio das fezes pelos animais dentro das baias, assim, procurou-se o máximo de aproximação com realidade em uma pastagem.

Durante 90 dias as fezes foram irrigadas diariamente com $6 \mathrm{~mm}$ de água, equivalendo a 6 litros de água por metro quadrado de área, de acordo com a precipitação média diária do período de verão-outono. As plântulas germinadas, de cada espécie, foram contadas aos 30,60 e 90 dias após terem sido ingeridas e defecadas. Os resultados foram transformados, para fins de análise de variância (Tukey a 5\%) em arcoseno da raiz quadrada da porcentagem de plantas germinadas em relação à 

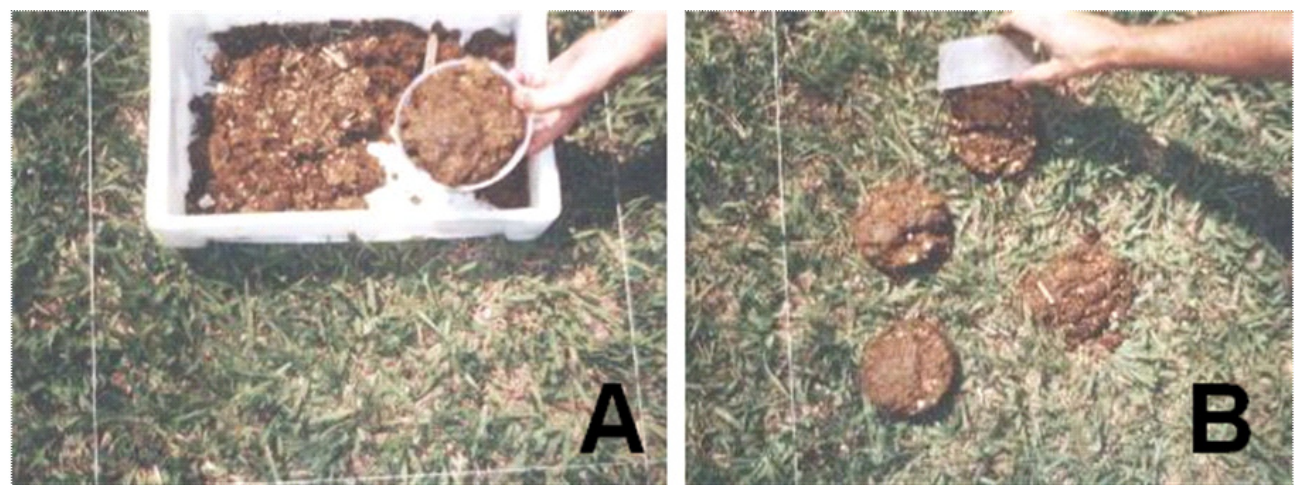

Figura 1. A. Confecção das placas fecais, B. Deposição das placas fecais, no campo de observação. (A. Bovine dung formation, B. Bovine dung dispose, on the observation field).

quantidade de sementes ingeridas, pois não seguiram distribuição normal, também foi realizado, em seguida, análise de regressão (Ferreira, 1999).

\section{RESULTADOSEDISCUSSÃO}

\section{GeRminaÇÃo ATÉ OS 30 diAS}

Os resultados de germinação aos 30 dias podem ser observados na tabela I. A análise da variância indicou diferença significativa para: espécies $(\mathrm{p}<0,01)$, período em que as fezes foram excretadas $(p<0,01)$ e interação entre espécie vs período em que as fezes foram excretadas $(p<0,01)$ com relação à porcentagem de plântulas germinadas nas placas fecais em relação ao total de sementes ingeridas (100\% igual a 200 sementes) na avaliação aos 30 dias após a excreção das fezes. A espécie que apre-

Tabela I. Porcentagem* de plântulas germinadas, em relação ao número total de sementes ingeridas (200), até os 30 dias pós-excreção das fezes, coletadas em períodos de 6 até 48 horas após ingestão. (Percentage of plants germinates, in relation to the total number of ingested seeds, even 30 days after crapted, collection at periods of 6 even 48 hours after eating).

\begin{tabular}{lcccccc}
\hline Período $(\mathrm{h})$ & Calopogônio & Cunhã & Leucena & Macrotiloma & Soja Perene & Média \\
0 a 6 & $0,00^{\mathrm{cA}}$ & $0,00^{\mathrm{bA}}$ & $0,00^{\mathrm{cA}}$ & $0,00^{\mathrm{cA}}$ & $0,00^{\mathrm{dA}}$ & $0,00^{\mathrm{e}}$ \\
6 a 12 & $0,00^{\mathrm{cB}}$ & $0,00^{\mathrm{bB}}$ & $0,00^{\mathrm{cB}}$ & $1,00^{\mathrm{bA}}$ & $1,00^{\mathrm{bcA}}$ & $0,40^{\mathrm{c}}$ \\
12 a 18 & $0,86^{\mathrm{bC}}$ & $1,38^{\mathrm{aBC}}$ & $0,00^{\mathrm{CD}}$ & $2,13^{\mathrm{aA}}$ & $1,50^{\mathrm{bB}}$ & $1,17^{\mathrm{a}}$ \\
18 a 24 & $1,75^{\mathrm{BBC}}$ & $1,75^{\mathrm{aBC}}$ & $0,00^{\mathrm{CD}}$ & $1,38^{\mathrm{bbC}}$ & $2,88^{\mathrm{aA}}$ & $1,56^{\mathrm{a}}$ \\
24 a 30 & $0,75^{\mathrm{bC}}$ & $1,88^{\mathrm{aA}}$ & $0,00^{\mathrm{cD}}$ & $1,25^{\mathrm{bBC}}$ & $0,88^{\mathrm{bcC}}$ & $0,95^{\mathrm{b}}$ \\
30 a 36 & $0,50^{\mathrm{bB}}$ & $1,63^{\mathrm{aA}}$ & $0,00^{\mathrm{cC}}$ & $0,50^{\mathrm{bB}}$ & $1,25^{\mathrm{bcA}}$ & $0,78^{\mathrm{b}}$ \\
36 a 42 & $0,00^{\mathrm{cC}}$ & $1,38^{\mathrm{aA}}$ & $0,75^{\mathrm{bB}}$ & $0,00^{\mathrm{CC}}$ & $0,75^{\mathrm{bcB}}$ & $0,58^{\mathrm{c}}$ \\
42 a 48 & $0,00^{\mathrm{cC}}$ & $0,00^{\mathrm{bC}}$ & $1,75^{\mathrm{aA}}$ & $0,00^{\mathrm{cC}}$ & $0,38^{\mathrm{cdBC}}$ & $0,43^{\mathrm{c}}$ \\
Total & $3,88^{\mathrm{C}}$ & $8,00^{\mathrm{AB}}$ & $2,50^{\mathrm{D}}$ & $6,25^{\mathrm{B}}$ & $8,63^{\mathrm{A}}$ & $\pm 5,85$ \\
CV\% médio & 25,70 & 22,86 & 23,71 & 30,53 & 60,56 & \\
\hline
\end{tabular}

aaBBMédias seguidas, na mesma coluna por letras minúsculas iguais, e na mesma linha por letras maiúsculas iguais, não diferem entre si pelo teste de Tukey a $5 \%$ de probabilidade.

*Cada valor apresentado na tabela, para espécie em cada período, representa a média de 5 repetições.

Archivos de zootecnia vol. 58, núm. 221, p. 76. 


\section{GERMINAÇÃO DE SEMENTES EM PLACAS FECAIS BOVINAS}

sentou maior porcentagem de sementes germinadas, no período de avaliação até 30 dias pós-excreção das fezes, foi à soja perene seguido pela cunhã. Contudo, as espécies apresentaram baixa quantidade de plantas germinadas nas fezes $(2,5-8,63 \%$ em relação ao total de sementes ingeridas). Estes resultados parecem estar de acordo com os relatados por Somarriba (1986) que estudando sementes de Psidium guajava L. observou baixa germinação nas fezes, todavia, notou que a passagem através do trato digestivo dos bovinos não afeta a germinação das sementes quando germinadas em laboratório. Janzen et al. (1985) em um estudo sobre a germinação de sementes de Enterolobium cyclocarpum escarificadas e não escarificadas submetidas à fermentação in vitro usando líquido ruminal (bovino) e inóculo cecal (eqüino), observaram que após 24 horas de exposição à fermentação in vitro, $90 \%$ das sementes escarificadas morre e que todas as sementes não escarificadas germinaram no teste de germinação. Sugerindo que a escarificação parece ser um processo crítico que afeta a sobre- vivência das sementes durante a passagem pelo trato digestivo dos grandes herbívoros. Além disso, dão a entender que as diferenças funcionais no estômago entre não ruminantes e ruminantes impõem testes padrões diferentes de mastigação e taxas de passagem nestes grupos, apontando estes fatores como os principais responsáveis pela porcentagem de germinação mais baixa em sementes encontradas nas fezes dos ruminantes.

\section{GerminaçÃo entre 30 e 60 dias}

Os resultados podem ser observados na tabela II. A análise da variância indicou diferença significativa para: espécies $(\mathrm{p}<0,01)$, período pós-ingestão das sementes $(\mathrm{p}<0,01)$, e interação entre espécie $v s$ período pós-ingestão das sementes em que as mesmas foram excretadas $(\mathrm{p}<0,01)$ com relação à porcentagem de plântulas germinadas nas placas fecais em relação ao total de sementes ingeridas (100\% igual a 200 sementes) na avaliação realizada entre 30 a 60 dias após a excreção das fezes. A espécie, que apresentou maior porcentagem de

Tabela II. Porcentagem* de plântulas germinadas, em relação ao número total de sementes ingeridas (200), dos 30 aos 60 dias pós-excreção das fezes, coletadas em períodos de 6 até 48 horas após ingestão. (Percentage of plants germinates, in relation to the total number of ingested seeds, between 30 even 60 days after crapted, collection at periods of 6 even 48 hours after eating).

\begin{tabular}{lcccccc}
\hline Período $(\mathrm{h})$ & Calopogônio & Cunhã & Leucena & Macrotiloma & Soja Perene & Média \\
0 a 6 & $0,00^{\mathrm{cA}}$ & $0,00^{\mathrm{cA}}$ & $0,00^{\mathrm{aA}}$ & $0,00^{\mathrm{aA}}$ & $0,00^{\mathrm{cA}}$ & $0,00^{\mathrm{e}}$ \\
6 a 12 & $0,00^{\mathrm{cB}}$ & $0,00^{\mathrm{cB}}$ & $0,00^{\mathrm{aB}}$ & $0,00^{\mathrm{aB}}$ & $0,50^{\mathrm{bA}}$ & $0,10^{\mathrm{d}}$ \\
12 a 18 & $0,87^{\mathrm{bB}}$ & $0,50^{\mathrm{bcC}}$ & $0,00^{\mathrm{aD}}$ & $0,39^{\mathrm{aC}}$ & $1,38^{\mathrm{aA}}$ & $0,63^{\mathrm{b}}$ \\
18 a 24 & $1,13^{\mathrm{aB}}$ & $2,38^{\mathrm{aA}}$ & $0,00^{\mathrm{aD}}$ & $0,25^{\mathrm{aC}}$ & $0,88^{\mathrm{abB}}$ & $0,93^{\mathrm{a}}$ \\
24 a 30 & $1,13^{\mathrm{aB}}$ & $2,13^{\mathrm{abA}}$ & $0,00^{\mathrm{aD}}$ & $0,75^{\mathrm{aC}}$ & $0,38^{\mathrm{bC}}$ & $0,89^{\mathrm{a}}$ \\
30 a 36 & $0,13^{\mathrm{cCD}}$ & $1,63^{\mathrm{abA}}$ & $0,50^{\mathrm{aC}}$ & $1,13^{\mathrm{aB}}$ & $0,00^{\mathrm{cD}}$ & $0,68^{\mathrm{b}}$ \\
36 a 42 & $0,13^{\mathrm{BC}}$ & $1,00^{\mathrm{abcA}}$ & $0,00^{\mathrm{aC}}$ & $0,00^{\mathrm{aC}}$ & $0,00^{\mathrm{cC}}$ & $0,23^{\mathrm{c}}$ \\
42 a 48 & $0,00^{\mathrm{cA}}$ & $0,00^{\mathrm{cA}}$ & $0,00^{\mathrm{aA}}$ & $0,00^{\mathrm{aA}}$ & $0,00^{\mathrm{cA}}$ & $0,00^{\mathrm{e}}$ \\
Total & $3,36^{\mathrm{AB}}$ & $7,63^{\mathrm{A}}$ & $0,50^{\mathrm{B}}$ & $2,50^{\mathrm{B}}$ & $3,13^{\mathrm{B}}$ & $\pm 3,42$ \\
CV\% médio & 89,10 & 76,41 & 0,00 & 96,36 & 65,10 & \\
\hline
\end{tabular}

aaBBMédias seguidas, na mesma coluna por letras minúsculas iguais, e na mesma linha por letras maiúsculas iguais, não diferem entre si pelo teste de Tukey a $5 \%$ de probabilidade.

*Cada valor apresentado na tabela, para espécie em cada período, representa a média de 5 repetições. 
sementes germinadas, no período de avaliação dos 30 aos 60 dias pós-excreção das sementes, foi a cunhã, seguida pelo calopogônio e a soja perene. Entretanto, os resultados encontrados mantiveram-se baixos e semelhantes aos observados na avaliação realizada aos 30 dias após excreção das fezes. O que nos leva a crer que as sementes foram mortas durante a passagem pelo trato digestivo dos bovinos ou sobreviveram, mas permaneceram dormentes não germinando, concordando com Manhães et al. (2003) e Chang et al.(2005), entre outros autores.

\section{GeRminaÇÃototal ATÉ OS 90 dias}

A análise da variância indicou diferença para espécies $(p<0,01)$, período pósingestão das sementes $(p<0,01)$, e interação entre espécie $v s$ período pós-ingestão das sementes $(p<0,01)$ com relação à porcentagem de plântulas germinadas nas placas fecais, lembrando que o número total de sementes ingeridas é igual a 200 sementes ou $100 \%$. A espécie que apresentou maior número de plântulas germinadas nas placas fecais, conforme resultados apresentados na tabela III, foi a cunha seguida pela soja perene, macrotiloma e calopogônio. Na figura 2 podemos observar plântulas de cunhã a germinar na placa ou escudo fecal. O período pós-ingestão das sementes em que foram excretadas as fezes que apresentou maior porcentagem de plântulas germinadas, em relação ao somatório total de plantas germinadas em todos os intervalos (102 igual a $100 \%$ ), foi o de 18 a 24 horas seguido do período de 24 a 30 horas, conforme tabela III. Estes resultados estão de acordo com os encontrados por Ghassali et al. (1998) que avaliando a dispersão de sementes por ovinos para a recuperação de pastagens degradadas no norte da Syria, observaram taxa máxima de recuperação até $36 \mathrm{~h}$ após a ingestão das sementes para todas as espécies estudadas, que todas as sementes foram recuperadas até $120 \mathrm{~h}$ e que $90 \%$ das sementes foram recuperadas até $72 \mathrm{~h}$. No

Tabela III. Porcentagem* de plântulas germinadas, em relação ao número total de sementes ingeridas (200), até os 90 dias pós-excreção das fezes, coletadas em períodos de 6 até 48 horas após ingestão. (Percentage of plants germinates, in relation to the total number of eating seeds, even 90 days after crapted, collection at periods of 6 even 48 hours after eating).

\begin{tabular}{|c|c|c|c|c|c|c|c|}
\hline Período (h) & Calopogônio & Cunhã & Leucena & Macrotiloma & Soja Perene & Média & Total\# \\
\hline 0 a 6 & $0,00^{\mathrm{cA}}$ & $0,00^{\mathrm{cA}}$ & $0,00^{\mathrm{bA}}$ & $0,00^{\mathrm{bA}}$ & $0,00^{\mathrm{dA}}$ & $0,00^{\mathrm{e}}$ & $0,00^{\mathrm{e}}$ \\
\hline 6 a 12 & $0,00^{\mathrm{cc}}$ & $0,00^{\mathrm{cc}}$ & $0,00^{\mathrm{bc}}$ & $1,00^{\mathrm{abB}}$ & $1,50^{\mathrm{bc} A \mathrm{~B}}$ & $0,50^{\text {cd }}$ & $4,93^{\mathrm{de}}$ \\
\hline 12 a 18 & $2,25^{\mathrm{abAB}}$ & $1,88^{\mathrm{bB}}$ & $0,00^{\mathrm{bc}}$ & $2,50^{\mathrm{aA}}$ & $2,88^{\mathrm{abA}}$ & $1,90^{\mathrm{b}}$ & $18,72^{b}$ \\
\hline 18 a 24 & $2,88^{\mathrm{aC}}$ & $5,63^{\mathrm{aA}}$ & $0,00^{\mathrm{bD}}$ & $2,13^{\mathrm{ac}}$ & $4,38^{\mathrm{aB}}$ & $3,00^{a}$ & $29,56^{a}$ \\
\hline 24 a 30 & $1,88^{a b c}$ & $5,25^{\mathrm{aA}}$ & $0,00^{\mathrm{bD}}$ & $2,00^{\mathrm{aBC}}$ & $1,25^{\mathrm{bcdc}}$ & $2,08^{b}$ & $20,44^{b}$ \\
\hline 30 a 36 & $0,63^{\mathrm{bcc}}$ & $3,25^{\mathrm{bA}}$ & $0,50^{\mathrm{abc}}$ & $1,63^{\mathrm{aB}}$ & $1,25^{\mathrm{bcdB}}$ & $1,45^{b}$ & $14,29^{b c}$ \\
\hline 36 a 42 & $0,13^{\mathrm{CCD}}$ & $2,38^{\mathrm{bA}}$ & $0,75^{\mathrm{abB}}$ & $0,00^{\mathrm{bD}}$ & $0,75^{\mathrm{cdB}}$ & $0,80^{c}$ & $7,88^{\mathrm{cd}}$ \\
\hline 42 a 48 & $0,00^{\mathrm{cc}}$ & $0,00^{\mathrm{cc}}$ & $1,75^{\mathrm{aA}}$ & $0,00^{\mathrm{bc}}$ & $0,375^{\mathrm{cdBC}}$ & $0,43^{d}$ & $4,19^{\mathrm{de}}$ \\
\hline Total & $7,77^{\mathrm{B}}$ & $18,38^{A}$ & $3,00^{C}$ & $9,25^{\mathrm{B}}$ & $12,38^{\mathrm{B}}$ & $\pm 10,16$ & 100 \\
\hline CV\% médio & 14,40 & 6,02 & 5,50 & 10,62 & 19,39 & & \\
\hline
\end{tabular}

ааввMédias seguidas, na mesma coluna por letras minúsculas iguais, e na mesma linha por letras maiúsculas iguais, não diferem entre si pelo teste de Tukey a $5 \%$ de probabilidade.

*Cada valor apresentado na tabela, para espécie em cada período, representa a média de 5 repetições. \#porcentagem em relação à soma total de plântulas germinadas em todos os períodos (100\% igual a 102 sementes).

Archivos de zootecnia vol. 58, núm. 221, p. 78. 


\section{GERMINAÇÃO DE SEMENTES EM PLACAS FECAIS BOVINAS}

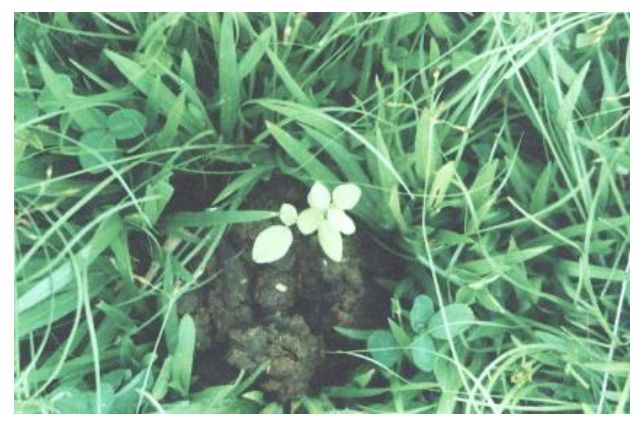

Figura 2. Plântulas de Clitorea ternatea germinadas em uma placa fecal bovina. (Clitorea ternatea plants in bovine dung).

presente estudo, a taxa máxima de recuperação também foi até $36 \mathrm{~h}$ após a ingestão das sementes $(90 \%$ das sementes germinadas). Gardener et al. (1993) em um estudo sobre a germinação de sementes de 10 leguminosas e 8 gramíneas tropicais e subtropicais após passagem através do trato digestivo dos bovinos até o período $160 \mathrm{~h}$, onde a germinação foi acompanhada nas placas fecais sendo semelhante ao presente estudo, observaram que o total de sementes germinadas de leguminosas foi maior que o das gramíneas. Mostrando que as leguminosas resistem melhor à passagem pelo trato digestivo dos bovinos. Também observaram marcada variação entre as espécies de leguminosas (0-78\%), variação explicada pelos mesmos por 3 fatores: gravidade específica, proporção de sementes duras e tamanho das sementes.

Os resultados da interação entre espécie vs período pós-ingestão das sementes podem ser melhor visualizados na figura 3 , no entanto não nos permite explicar o comportamento germinativo das leguminosas nas fezes. Contudo é claramente visível a grande diferença entre a espécie leucena e as demais, pois a mesma seguiu um comportamento totalmente diferente com respeito à demais. Por outro lado, os resultados obtidos no presente estudo estão dentro do patamar de $23 \%$ de germinação descrito por Harmor e Kein (1934) e com certeza estão relacionados à quantidade de sementes que resistiram intactas à passagem pelo trato digestivo dos bovinos. Por outro lado, o que pode ter afetado os resultados foi o tipo de alimentação oferecida, isso porque segundo Machado et al. (1997) o principal fator que afeta o tempo de passagem do alimento pelo trato digestivo é a qualidade da dieta.

Prasad et al. (2006) estudando o processo de dispersão de sementes de Phyllanthus emblica por ruminantes em florestas tropicais observou que o cervo Gamo Axiado (Axis deer) reguzgita sementes intatas após tê-las retido no rúmen por 7 - 27 h e que uma fração considerável de sementes germina $(22 \%)$, embora a porcentagem de germinação original das sementes consumidas seja de 72\%. Já Michael et al. (2006) avaliando o efeito da digestão e mastigação de sementes de Malva parviflora L. por ovinos sobre a germinação observaram que após $12 \mathrm{~h}$ de exposição à digestão ruminal $\mathrm{a}$ germinação das sementes previamente escarificadas decai de 99,2 para $1,4 \%$ e nos períodos mais longos de exposição nenhuma semente germina. Além disso, observou que as sementes não escarificadas incubadas in situ apresentam elevada porcentagem de germinação, independente do período de incubação. E no ensaio com sementes não escarificadas colocadas misturadas ao alimento concentrado, na qual as fezes foram coletadas posteriormente (entre 6 e $120 \mathrm{~h}$ após a alimentação), observaram que a principal excreção de sementes nas fezes começou após 12 h e continuou até 144 h, com picos entre 36 e $72 \mathrm{~h}$ após o consumo. E que embora a mastigação e a passagem pelo rúmen afetem letalmente a maioria das sementes não escarificadas, aproximadamente $20 \%$ foram recuperadas intactas e $90 \%$ destas se mostraram viáveis.

Pesquisando a germinação de sementes incubadas no rúmen de ovinos e caprinos, Robles e Castro (2002) observaram elevada taxa de germinação se o revestimento for corroído, o que ocorre quando as sementes 


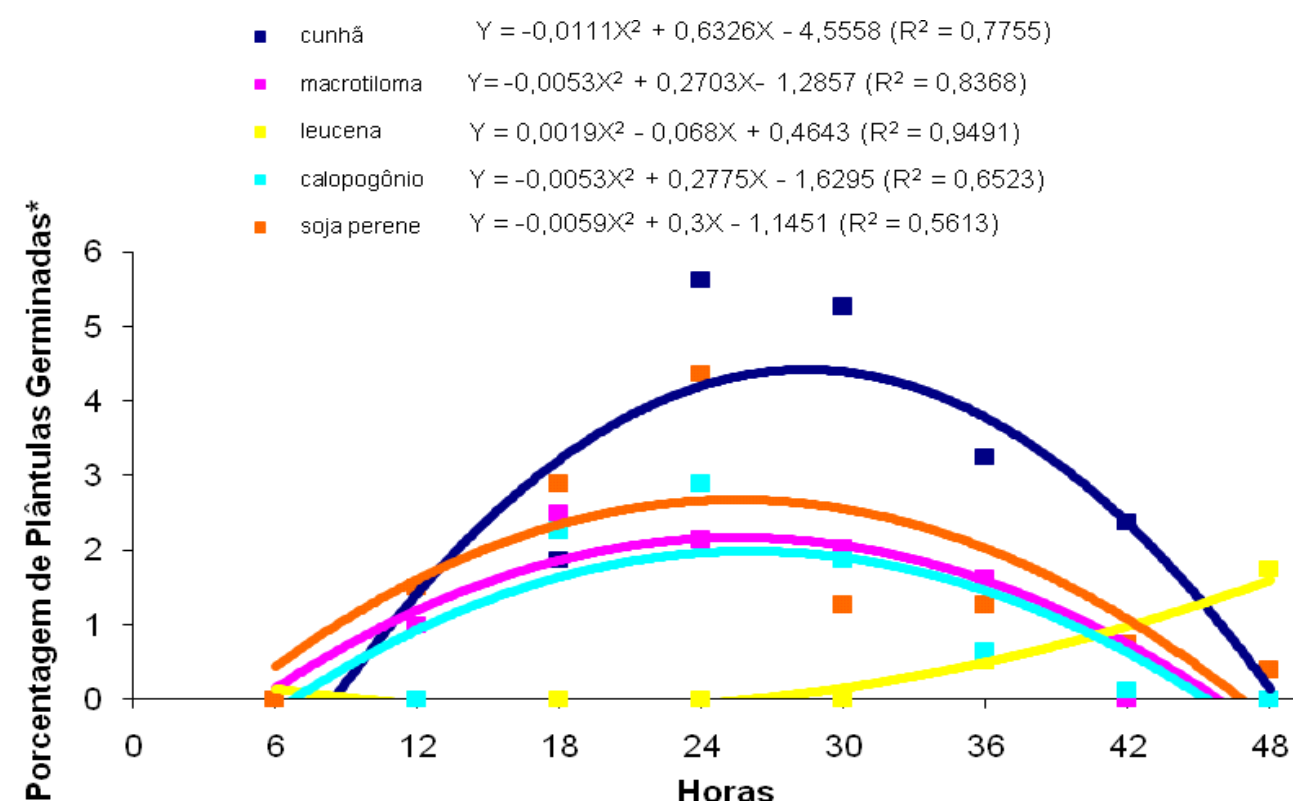

Figura 3. Regressão para porcentagem de plântulas germinadas, em relação ao número total de sementes ingeridas, em placas fecais bovinas à campo, no período em que foram excretadas. (Seeds germinate regression in bovine dung on the field, in relation to the total number of ingested seeds into the period what was crapped).

são incubadas no rúmen $(32 \%$ até $48 \mathrm{~h}$ de incubação ruminal contra $12 \%$ para o controle). Mouissie et al. (2005) estudando a sobrevivência de sementes de 25 espécies de plantas introduzidas na alimentação de cervos (Dama dama L), observaram que 24 das 25 espécies de plantas ingeridas pelos animais sobreviveram e germinaram nas fezes $(0,5-42 \%$ das sementes ingeridas $)$ e que $50 \%$ de todas as sementes foram recuperadas no período de até $25 \mathrm{~h}$, variando de 13 a 38 h. Também foi observada correlação negativa entre sobrevivência das sementes e a massa das sementes $(R=0,65)$ e as dimensões das mesmas $(\mathrm{R}=0,56)$. Robles et al. (2005) estudaram a germinação de sementes de Adenocarpus decorticans Boiss e Retama sphaerocarpa (L.) Boiss, após incubação ruminal em caprinos durante 24,48 e 72 h e através da passagem pelo trato digestivo de caprinos, testando a germinação das sementes nas fezes, e observaram que a recuperação de sementes após passagem pelo trato digestivo foi de 7,4\% para Adenocarpus e 17,4\% para Retama, e que as sementes de Retama quebradas parcialmente pela mastigação, mas não destruídas, apresentaram uma elevada porcentagem de germinação (média de 50\%).

No presente estudo um alimento de baixa qualidade nutricional foi oferecido aos animais, assim se alimentos com maior qualidade tivessem sido oferecidos provavelmente os resultados teriam sido diferentes, justamente por causa da permanência no trato digestivo. Outros fatores podem ter sido determinantes para a observação dos resultados deste estudo, dentre eles destacamos: a fermentação das fezes no campo, a alta contaminação por fungos e bactérias, o posicionamento das sementes no bolo fecal, a espessura do bolo fecal, a desidra- 


\section{GERMINAÇÃO DE SEMENTES EM PLACAS FECAIS BOVINAS}

tação da superfície do bolo fecal e um fator de extrema importância, a dureza do tegumento. Segundo Simão Neto e Jones (1987) têm estreita relação com a composição do tegumento das sementes, desta forma o tegumento é considerado um dos principais condicionantes da germinação, do vigor e da longevidade de sementes. E a compreensão de sua estrutura e propriedades pode contribuir para explicar, antecipar ou alterar o comportamento de sementes sob determinadas condições ambientais. Grande parte das características do tegumento está associada a problemas específicos apresentados pelas sementes, assim, por exemplo, suceptibilidade a danos mecânicos está associada ao seu teor de lignina, enquanto que longevidade e potencial de deterioração no campo têm sido relacionados ao grau de permeabilidade do tegumento (Souza e Marcos-Filho, 2001). As leguminosas apresentam latência física das sementes devido à presença de um tegumento duro e impermeável, assim precisam ser escarificadas para germinar (Izhaki e Ne'eman, 1997). Em Salta, província da região do Chaco da Argentina, Ortega et al. (2001) examinando a germinação de sementes Caesalpinia paraguariensis após passagem pelo trato digestivo de bovinos, notaram baixa taxa de germinação das sementes e que a porcenagem de germinação não aumenta, isto porque as sementes viáveis estão dormentes devido ao seu forte tegumento impermeável. Para Peco et al. (2006) espécies com tegumentos impermeáveis apresentam maiores porcentagens de germinação após passagem pelo trato digestivo de bovinos, embora nenhuma diferença significativa possa ser notada na sobrevivência ou a velocidade de germinação. Essa idéia, de que a latência se rompe quando as sementes passam as pelo trato digestivo de animais, é amplamente aceita, no entanto, existem resultados contraditórios (Izhaki e Ne'eman, 1997; Campos e Ojeda, 1997; Ortega, 1999; Manhães et al., 2003; Chang et al., 2005).
As equações que descrevem o comportamento do número de plântulas nas placas fecais, observadas no presente estudo, foram obtidas por meio de análise de regressão e estão dispostas na figura 3. O comportamento observado pelas curvas já era esperado, haja vista os resultados apresentados nas tabelas I, II e III, além da freqüência de evacuações por dia de 4 a 14 (Costa, 1988; MacDiarmid e Watkins, 1972; Simpson e Stobbs, 1979) e do total de matéria fresca produzida por um bovino adulto - 25 $\mathrm{kg} / \mathrm{dia}$ (CNPGL, 1984). Com isso, a observação das curvas nos permite confirmar que a cunhã foi a que apresentou o maior número de sementes germinadas nas fezes, e que a soja perene foi semelhante ao calopogônio e ao macrotiloma e que, além disso, o período em que as sementes começam a ser excretadas, de forma considerável, foi de 12 até 42 horas após a ingestão, sendo essa faixa uma importante ferramenta a ser utilizada no manejo de sementes na pastagem. Estes resultados nos sugerem, inicialmente, que o tamanho das sementes não foi um fator limitante à germinação nas fezes bovinas. Isto porque, as espécies que apresentaram resultados mais expresivos diferenciam-se pelo tamanho de suas sementes, o que foi o caso da cunhã e da soja perene. Deminicis et al. (2005) estudando a influência do tamanho das sementes sobre a germinação de leguminosas tropicais observou que correlação positiva $(\mathrm{R}=0,42)$ entre o tamanho e a porcentagem média de germinação de sementes e também correlação positiva $(\mathrm{R}=$ 0,39 ) entre o tamanho e o índice de velocidade de emergência das sementes, discordando dos resultados observados no presente estudo. Peco et al. (2006) ponderaram sobre a importância do tamanho da semente, da forma e da impermeabilidade do tegumento no processo endozoocoria e dispersão de 20 espécies abundantes das pastagens centrais da península ibérica (Europa). Para isso estudaram a sobrevivência, a porcentagem de germinação e a velocidade 
de passagem de sementes pelo trato digestivo de ovinos e observaram que todas as espécies estudadas mostraram baixa sobrevivência ao tratamento de mastigação e incubação ruminal. Além disso, as espécies com sementes grandes apresentaram porcentagens mais elevadas de sobrevivência do que as espécies com sementes pequenas. Contudo, Ghassali et al. (1998) postulou que espécies que possuem sementes pequenas passam mais rapidamente através do trato digestivo de ovinos e em maior número (58-72\%) do que sementes das espécies com sementes grandes (10$40 \%$ ), assim aumentam o estabelecimento de espécies à campo sob circunstâncias do estresse hídrico. Jones et al. (1991) avaliaram a germinação de sementes de diversas espécies por 11 anos no estado de Queensland, sudeste da Austrália, coletando fezes bovinas em 2 tipos de pastagem de Setaria sphacelata (consorciada com Macroptilium atropurpureum e não consorciada) sob diferentes taxas de lotação (alta e baixa), na primavera, verão, outono e inverno. E observaram que a porcentagem de sementes germinadas nas fezes foi mais elevada no verão-outono do que no inverno-primavera, e nos piquetes com altas taxa de lotação que nos com baixa taxa de lotação. Bråthen et al. (2007) em Finnmark, Noruega, estudaram a germinação de sementes em fezes de Alces (Alces alces) e a lotação animal sobre as mesmas e observaram que a composição botânica do pasto é composta, em sua maioria, pelas espécies que possuem o maior número de plântulas emergidas nas fezes e além disso que as densidades animais mais elevadas proporcionaram maior abundância de fezes com estas contendo poucas espécies de plantas emergentes. Este fato demonstra que os ruminantes

\section{BIBLIOGRAFIA}

Blackshaw, R.E. and L.M. Rode. 1991. Effect of ensiling and rumen digestion by cattle on weed seed viability. Weed Sci., 39: 104-108. podem neutralizar o impacto negativo do pastejo pelo retorno de sementes viáveis em suas fezes. Gardener et al. (1993) considera que há um considerável potencial para a introdução de leguminosas com sementes duras semeadas por bovinos em pastagens, como por exemplo o Stylosanthes sp.

\section{CONCLUSÃO}

A cunhã $(18,38 \%)$ foi a espécie que apresentou maior porcentagem de plântulas germinadas nas placas fecais bovinas, seguida da soja perene $(12,38 \%)$, macrotiloma $(9,25 \%)$ e calopogônio $(7,77 \%)$. O intervalo de horas, em que foram excretadas as fezes, que apresentou maior porcentagem de plântulas foi o de 18 a 24 horas com 29,56\% das plântulas germinadas em relação ao somatório total de plântulas germinadas em todos os períodos, seguido do período de 24 a 30 horas com $20,44 \%$. A taxa máxima de recuperação de sementes germinadas ocorreu, até 90 dias, no período de até $36 \mathrm{~h}$ após a ingestão das sementes $(90 \%$ das sementes germinadas). Os resultados deste estudo sugerem que os bovinos podem ser eficientes dispersores de espécies de leguminosas e que o seu uso é um modo prático e barato de introdução de leguminosas para a melhora ou recuperação de pastagens degradadas no Brasil. Contudo, novos estudos se fazem necessários para aprimoramento da técnica com possíveis recomendações de uso.

\section{AGRADECIMENTOS}

Sinceros agradecimentos às seguintes instituições e as pessoas que as compõem, sem as quais o presente trabalho teria sido impossível: À FAPERJ, UFRRJ, PESAGRORIO,EMBRAPA-AGROBIOLOGIA UUENF.

Bråthen, K.A., V.T. González, M. Iversen, S. Killengreen, V.T. Ravolainen, R.A. Ims and N.G. Yoccoz. 2007. Endozoochory varies with

Archivos de zootecnia vol. 58, núm. 221, p. 82. 


\section{GERMINAÇÃO DE SEMENTES EM PLACAS FECAIS BOVINAS}

ecological scale and context. Ecography, 30: 308-320.

Bruun, H.H and P. Poschlod. 2006. Why are small seeds dispersed through animal guts: large numbers or seed size per se? Oikos, 11: 402411.

Campos, M. and R. Ojeda. 1997. Dispersal and germination of Prosopis flexuosa (Fabaceae) seeds by desert mammals in Argentina. J. Arid Environ., 35: 707-714.

Chang, E.R., E.L. Zozaya, D.P.J. Kuijper and J.P. Bakker. 2005. Seed dispersal by small herbivores and tidal water: are they important filters in the assembly of salt-marsh communities? Funct. Ecol., 19: 665-673.

CNPGL, 1984. Biogás: Energia do meio rural para o meio rural. Centro Nacional de Pesquisa do Gado de Leite. Embrapa. Folheto.

Costa, M.J.R.P. 1988. Padrões de comportamento de defecação e micção de vacas holandesas em lactação. Em: Anais... IV Encontro Anual de Ecologia, Florianópolis, SC. p.152.

Deminicis, B.B., J.C. Almeida, M.C. Blume e M.F. Souza. 2005. Influência do tamanho das sementes sobre a germinação de oito leguminosas tropicais. Em: VII Congresso Internacional de Zootecnia, ZOOTEC'2005. Campo Grande. 2005. Anais... Campo Grande.

Ferreira, D.F. 1999. SISVAR 4.3. Sistema de análises estatísticas. CD-ROM. Universidade Federal de Lavras, UFLA. Lavras, MG.

Ferreira, E., G.C. Rocha, S.P. Braz, J.C. Soares e F.A.A. Andrade. 2004. Modelos estatísticos para o estudo da distribuição de excretas de bovinos em pastagens tropicais e sua importância na sustentabilidade desses sistemas. Livest. Res. Rural Develop., 16. Art. 66. http://www.cipav.org.co//rrd//rrd16/9/ ferr16066.htm. Acceso em: 1 janeiro 2008.

Gardener, C.J., J.G. Mclvor and A. Jansen. 1993. Passage of legume and grass seeds through the digestive tract of cattle and their survival in faeces. J. Appl. Ecol., 30: 63-74.

Ghassali, F., A.E. Osman and P.S. Cocks. 1998. Rehabilitation of degraded grasslands in North Syria: the use of Awassi sheep to disperse the seeds of annual pasture legumes. Exp. Agr., 34: 391-405.

Greenhalgh, J.F.D. and G.W. Reid. 1968. The effects of grazing intensity on herbage consumption and animal production. III Dairy cows grazed at two intensities on clean or contaminated pasture. J. Agr. Sci., 71: 223-228.

Grelle, C.E.V. and Q.S. Garcia. 1999. Potential dispersal of Cecropia hololeuca by the common opossum (Didelphis aurita) in Atlantic Forest, Southeastern Brazil. Rev. Ecologie (Terre et Vie), 54: 327-332.

Harmor, G.W. and F.D. Kein. 1934. The percentage and viability of weed seeds recovered in feces of farm animals and their longevity when buried in manure. J. Amer. Soc. Agron., 26: 762-767. Hirata, M., Y. Sugimoto and M. Ueno. 1997. Distribution of dung pats and ungrazed areas in bahiagrass (Paspalum notatum Flügge). Grassland Sci., 33: 128-139.

Izhaki, I. and G. Ne'eman. 1997. Hares (Lepus spp.) as seed dispersers of Retama raetam (Fabaceae) in a sandy landscape. J. Arid Environ., 37: 343-354.

Janzen D.H., M.W. Demment and J.B. Robertson. 1985. How fast and why do germinating guanacaste seeds (Enterolobium cyclocarpum) die inside cows and horses? Biotropica, 17: 322-325.

Jones, R. M., M. Noguchi, and G.A. Bunch. 1991. Levels of germinable seed in topsoil and cattle faeces in legume-grass and nitrogen-fertilized pastures in south-east Queensland. Aust. J. Exp. Agr., 42: 953-968.

Jones, R.M. and M. Simão Neto. 1987. Recovery of pasture seed ingested by ruminants. 3 . The effects of the amount of seed in the diet and of diet quality on seed recovery from sheep. Aust. J. Exp. Agr., 27: 253-256.

MacDiarmid, B.N. and B.R. Watkins. 1972. The cattle dung patch. 3: Dsitribution and rate of decay of dung patches their influence on grazing behaviour. J. Brit. Grassland Soc., 27: 48-54.

Machado, L.A.Z., C.S. Nicoloso e A.V.A. Jacques. 1997. Percentagem e dureza do tegumento de sementes de três espécies forrageiras recuperadas em fezes ovinas. Rev. Bras. Zootecn., 26: 42-45.

Manhães, M.A., L.C.S. Assis e R.M. Castro. 2003. Frugivoria e dispersão de sementes de Miconia urophylla (Melastomataceae) por aves em um fragmento de Mata Atlântica secundária em Juiz de Fora, Minas Gerais, Brasil. Ararajuba, 11: 173-180.

Archivos de zootecnia vol. 58, núm. 221, p. 83. 


\section{DEMINICIS, ALMEIDA, MALAFAIA, BLUME, ABREUE VIEIRA}

Michael, P.J., K.J. Steadman, J.A. Plummer and P. Vercoe. 2006. Sheep rumen digestion and transmission of weedy Malva parviflora seeds. Aust. J. Exp. Agric., 46: 1251-1256.

Mouissie, A.M., C.E.J.V.D. Veen, G.F. Veen and R.V. Diggelen. 2005. Ecological correlates of seeds survival after ingestion by fallow deer. Funct. Ecol., 19: 284-290.

Ortega, B.P. 1999. Emergencia y supervivencia de plántulas de Prosopis ferox en el Parque Nacional Los Cardones (Salta, Argentina). Tesis de Licenciatura. Universidad Nacional de Salta, Salta, Argentina.

Ortega, B.P., M.L. Viana, G. Larenas y M. Saravia. 2001. Germinación de semillas de Caesalpinia paraguariensis (Fabaceae): agentes escarificadores y efecto del ganado. Rev. Biol. Trop., 49: 301-304.

Peco, B., L. Lopez-Merino and M. Alvir. 2006. Survival and germination of Mediterranean grassland species after simulated sheep ingestion: ecological correlates with seed traits. Acta Oecol., 30: 269-275.

Prasad, S., J. Krishnaswamy, R. Chellam and S.P. Goyal. 2006. Ruminant-mediated seed dispersal of an economically valuable tree in Indian dry forest. Biotropica, 38: 679-682.

Robles, A. and J. Castro. 2002. Effect of thermal shock and ruminal incubation on seed germination in Helianthemum apenninum (L.) Mill.
(Cistaceae). Acta Bot. Malacitana, 27: 41-47

Robles, A., J. Castro, E. González-Miras and M.E. Ramos. 2005. Effects of ruminal incubation and goat's ingestion on seed germination of two legume shrubs: Adenocarpus decorticans Boiss. and Retama sphaerocarpa (L.) Boiss. Options Méditerranéennes. Serie A: Séminaires Méditerranéennes, 67: 111-115.

Simão Neto, M. and R.M. Jones. 1987. Recovery of pasture seed ingested by ruminats.2. Digestion of seed in sacco and in vitro. Recovery of 1987. Aust. J. Exp. Agric., 27: 247-251.

Simpson, J. and T.H. Stobbs. 1979. Nitrogen supply and animal production from pastures. In: Morley F.H.W. (Editor). Grazing animal world animal science. b1, Chapter 14. Elsevier Scientific Publications. Amsterdam. p. 261-287.

Somarriba, E. 1986. Effects of livestock on seed germination of guava (Psidium guajava L.). Agroforest. Syst., 4: 233-238.

Souza, F.H.D. and J. Marcos-Filho. 2001. The seed coat as a modulator of seed-environment relationships in Fabaceae. Rev. Bras. Bot., 24: 365375.

Wenny, D.G. 2000. Seed dispersal, seed predation, and seedling recruitment of a neotropical montane tree. Ecol. Monogr., 70: 331-351.

Wenny, D.G. and D.J Levey. 1998. Directed seed dispersal by bellbirds in a tropical cloud forest. Proc. Natl. Acad. Sci., 95: 6204-6207.

Archivos de zootecnia vol. 58, núm. 221, p. 84. 